James W. Welsh, Ritsuko Komaki, Arya Amini, Mark F. Munsell, Wyatt Unger, Pamela K. Allen, Joe Y. Chang, Jeffrey S. Wefel, Susan L. McGovern, Su S. Chen, Zhongxing Liao, Paul Brown, Erik Sulman, John V. Heymach, and Edward S. Kim, The University of Texas MD Anderson Cancer Center, Houston TX; and Linda L. Garland, Jamie Holt, and Baldassarre Stea, The Arizona Cancer Center, Tucson, AZ.

Published online ahead of print at www.jco.org on January 22, 2013.

Supported by OSI Pharmaceuticals; Genentech; Paul Calabresi Award in Clinical Oncology (K12; J.W.W.), and Grants No. U10 CA21661 (R.K.) and No. P30 CA016672 (to MD Anderson Cancer Center) from the National Cancer Institute; the Lung Cancer Research Foundation; Contract No. CS2008-00022496DH from Accuray; and the family of Mr. M. Adnan Hamed.

Authors' disclosures of potential conflicts of interest and author contributions are found at the end of this article.

Clinical trial information: NCT00871923.

Corresponding author: James W

Welsh, MD, Department of Radiation Oncology, Unit 97, The University of

Texas MD Anderson Cancer Center, 1515 Holcombe Blvd, Houston, TX

77030; e-mail: jwelsh@mdanderson.org

(c) 2013 by American Society of Clinical Oncology

0732-183X/13/3107-895/\$20.00

DOI: 10.1200/JCO.2011.40.1174

\title{
Phase II Trial of Erlotinib Plus Concurrent Whole-Brain Radiation Therapy for Patients With Brain Metastases From Non-Small-Cell Lung Cancer
}

James W. Welsh, Ritsuko Komaki, Arya Amini, Mark F. Munsell, Wyatt Unger, Pamela K. Allen, Joe Y. Chang, Jeffrey S. Wefel, Susan L. McGovern, Linda L. Garland, Su S. Chen, Jamie Holt, Zhongxing Liao, Paul Brown, Erik Sulman, John V. Heymach, Edward S. Kim, and Baldassarre Stea

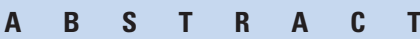

\section{Purpose}

Brain metastasis (BM) is a leading cause of death from non-small-cell lung cancer (NSCLC). Reasoning that activation of the epidermal growth factor receptor (EGFR) contributes to radiation resistance, we undertook a phase II trial of the EGFR inhibitor erlotinib with whole-brain radiation therapy (WBRT) in an attempt to extend survival time for patients with BM from NSCLC. Additional end points were radiologic response and safety.

\section{Patients and Methods}

Eligible patients had BM from NSCLC, regardless of EGFR status. Erlotinib was given at $150 \mathrm{mg}$ orally once per day for 1 week, then concurrently with WBRT (2.5 Gy per day 5 days per week, to 35 Gy), followed by maintenance. EGFR mutation status was tested by DNA sequencing at an accredited core facility.

\section{Results}

Forty patients were enrolled and completed erlotinib plus WBRT (median age, 59 years; median diagnosis-specific graded prognostic assessment score, 1.5). The overall response rate was $86 \%$ $(n=36)$. No increase in neurotoxicity was detected, and no patient experienced grade $\geq 4$ toxicity, but three patients required dose reduction for grade 3 rash. At a median follow-up of 28.5 months (for living patients), median survival time was 11.8 months $(95 \% \mathrm{Cl}, 7.4$ to 19.1 months). Of 17 patients with known EGFR status, median survival time was 9.3 months for those with wild-type EGFR and 19.1 months for those with EGFR mutations.

\section{Conclusion}

Erlotinib was well tolerated in combination with WBRT, with a favorable objective response rate. The higher-than-expected rate of EGFR mutations in these unselected patients raises the possibility that EGFR-mutated tumors are prone to brain dissemination.

\section{J Clin Oncol 31:895-902. (C) 2013 by American Society of Clinical Oncology}

\section{INTRODUCTION}

Lung cancer continues to be the leading cause of cancer-related mortality for both men and women, with an estimated 222,520 new lung cancer cases diagnosed in the United States each year. ${ }^{1}$ Unfortunately, despite advances in treatment, the prognosis for patients with advanced lung cancer remains poor, with the vast majority of patients dying as a result of uncontrolled systemic disease. Among patients with non-small-cell lung cancer (NSCLC), approximately $20 \%$ to $40 \%$ will develop brain metastases at some point. ${ }^{2,3}$ Treatment options for brain metastases from NSCLC include whole-brain radiation therapy (WBRT), stereotactic radiosurgery, surgical resection, or some combination of the three. The median survival time after WBRT corre- lates strongly with the patient's age, performance score, and number and location of metastatic lesions and generally ranges from 3 to 6 months. ${ }^{4-8}$

The epidermal growth factor receptor (EGFR), a member of the ErbB family of receptor tyrosine kinases, is abnormally activated in epithelial cancers, including NSCLC. ${ }^{9,10}$ Erlotinib, a small-molecule inhibitor of the EGFR pathway, has been shown to improve survival in NSCLC when used as maintenance therapy, ${ }^{10}$ with the greatest benefit observed for the $10 \%$ to $15 \%$ of patients with EGFR mutations. $^{10,11}$ Radiation increases the expression of EGFR in cancer cells, possibly contributing to the resistance of those cells to therapy. ${ }^{12,13}$ Overexpression of EGFR by tumors is also associated with reduced local control after radiation. ${ }^{14}$ Blockade of EGFR signaling in vitro has been shown to sensitize 
cells to the effects of radiation. ${ }^{12}$ Further, blockade of the wild-type EGFR has also been demonstrated to reduce radiation resistance through three separate mechanisms: by reducing DNA repair, by inhibiting antiapoptotic pathways, and by reducing proliferation. ${ }^{12}$

The clinical use of EGFR inhibitors with concurrent radiation therapy is currently being investigated in several trials, including the Radiation Therapy Oncology Group 0617 (RTOG 0617) trial. Because the small-molecule EGFR inhibitor erlotinib has shown some evidence of blood-brain barrier penetration, ${ }^{15,16}$ we hypothesized that EGFR inhibition could be combined with WBRT to enhance the therapeutic ratio by selectively targeting the cancer cells within the brain, thereby extending survival without increasing the neurotoxicity associated with WBRT. We tested this hypothesis in NCT00871923 [Tarceva With Whole Brain Radiation Therapy-Brain Mets From Non-Small Cell Lung Cancer], a phase II clinical trial of erlotinib and concurrent WBRT for patients with brain metastases from NSCLC.

\section{PATIENTS AND METHODS}

\section{Eligibility Criteria}

Eligibility criteria included newly radiographically diagnosed brain metastasis from NSCLC, with or without prior craniotomy or stereotactic radiosurgery; age 18 years or older; Karnofsky performance score (KPS) $\geq 70$; and evidence of normal hematologic and hepatic function during the 30 days before starting the protocol treatment. Exclusion criteria included any uncontrolled or symptomatic major medical illnesses such as AIDS or neurologic/ psychiatric illnesses such as Alzheimer's disease.

\section{Study Design}

This prospective phase II study was conducted jointly by the University of Arizona (beginning in January 2006) and at the MD Anderson Cancer Center (beginning in January 2009). Twenty patients from each site (for a total of 40 patients) were combined for statistical analysis. The primary end point was improvement in median survival compared with that of historical controls. Among the 20 patients treated at the MD Anderson Cancer Center, 17 had EGFR mutation testing of the original (primary) lung tumor. This investigator-initiated study was jointly sponsored by OSI Pharmaceuticals (Melville, NY) and Genentech (South San Francisco, CA), both of which provided erlotinib for the study. The protocol was reviewed and approved by the institutional review boards and ethics committees of each institution. All patients provided written informed consent to participate, and the study was conducted in accordance with the Declaration of Helsinki.

After enrollment onto the study, patients were given a loading dose of erlotinib $150 \mathrm{mg}$ per day for 6 days, after which all patients received erlotinib $150 \mathrm{mg}$ per day concurrently with WBRT, followed by maintenance erlotinib (also at $150 \mathrm{mg}$ per day) until disease progression or until adverse effects became intolerable. Dose reduction was allowed for intolerable adverse effects (grade $\geq 3$ ) such as rash or diarrhea in 50-mg increments down from $150 \mathrm{mg}$ to $100 \mathrm{mg}$ and then to $50 \mathrm{mg}$ if needed.

Radiation therapy was initially delivered in 3-Gy fractions once per day 5 days per week to a total dose of $30 \mathrm{~Gy}$. However, concerns regarding possible neurotoxicity in two patients treated led to the WBRT dose being changed to 35 Gy to be delivered in 14 fractions of 2.5 Gy each after the first 10 patients had been treated. This change was based on published findings suggesting that use of smaller (lower-dose) fractions could reduce neurotoxicity. ${ }^{17-20}$ Radiation was delivered as opposed lateral 6-MV beams with a German helmet technique. ${ }^{21}$

\section{Patient Evaluations}

Before enrollment, all patients had a baseline evaluation that included a medical history, general physical examination, neurologic examination (including the Folstein Mini-Mental Status Examination ${ }^{22}$ ), complete blood count, and serum chemistries. Baseline evaluations were repeated at the completion of radia- tion, at 1 month of follow-up, and then every 3 months thereafter until death or loss to follow-up. Imaging evaluations (head magnetic resonance imaging scans) were obtained at baseline and then every 3 months until death. Toxicity was documented according to the Common Terminology Criteria for Adverse Events $\mathrm{V} 3.0^{23}$ once a week during treatment and then every 3 months at follow-up visits. Toxicity was reported as the highest grade experienced during the entire study. Neurologic examination and KPS were evaluated at baseline, at 6 months, and at 12 months after treatment. Patients also underwent formal cognitive testing before enrollment, within 14 days of WBRT completion, and at each follow-up visit. This testing consisted of a thorough neurologic examination, with assessment of alertness, orientation, language, speech, cranial nerves, motor strength, sensory deficits, and cerebellar function. Objective standardized cognitive tests that assess cognitive domains affected by brain tumors and treatment were administered by a neuropsychologist or trained psychometricians under the supervision of a neuropsychologist. These tests included the Hopkins Verbal Learning Test-Revised, for memory; the Trail Making Test Part A, for processing speed; and the Trail Making Test Part B and the Multilingual Aphasia Examination Controlled Oral Word Association test for executive function.

\begin{tabular}{|c|c|c|}
\hline Characteristic & $\begin{array}{l}\text { Value or No. of } \\
\text { Patients }\end{array}$ & $\%$ \\
\hline \multicolumn{3}{|l|}{ Age, years } \\
\hline Median & \multicolumn{2}{|l|}{59.0} \\
\hline Range & \multicolumn{2}{|l|}{$29-77$} \\
\hline \multicolumn{3}{|l|}{ Sex } \\
\hline Male & 17 & 42.5 \\
\hline Female & 23 & 57.5 \\
\hline \multicolumn{3}{|l|}{ Karnofsky performance score } \\
\hline 100 & 0 & 0 \\
\hline 90 & 13 & 32.5 \\
\hline 80 & 15 & 37.5 \\
\hline 70 & 11 & 27.5 \\
\hline 60 & 1 & 2.5 \\
\hline \multicolumn{3}{|l|}{ Race/ethnicity } \\
\hline White & 29 & 72.5 \\
\hline Hispanic or Latino & 5 & 12.5 \\
\hline Black & 4 & 10.0 \\
\hline Asian & 2 & 5.0 \\
\hline \multicolumn{3}{|l|}{ No. of brain metastases } \\
\hline $0-3$ & 18 & 45.0 \\
\hline $4-10$ & 15 & 37.5 \\
\hline$>10$ & 7 & 17.5 \\
\hline \multicolumn{3}{|l|}{ Smoking status } \\
\hline Prior & 23 & 57.5 \\
\hline Never & 11 & 27.5 \\
\hline Current & 5 & 12.5 \\
\hline Unknown & 1 & 2.5 \\
\hline \multicolumn{3}{|l|}{ Tumor histology } \\
\hline Adenocarcinoma & 30 & 75.0 \\
\hline Squamous & 2 & 5.0 \\
\hline Large cell & 8 & 20.0 \\
\hline \multicolumn{3}{|l|}{ GPA } \\
\hline 0.5 & 5 & 12.5 \\
\hline 1 & 10 & 25 \\
\hline 1.5 & 8 & 20 \\
\hline 2 & 6 & 15 \\
\hline 2.5 & 7 & 17.5 \\
\hline 3 & 4 & 10 \\
\hline \multicolumn{3}{|c|}{ Active extracranial disease at study entry } \\
\hline Yes & 28 & 70.0 \\
\hline No & 12 & 30.0 \\
\hline
\end{tabular}

Abbreviation: GPA, graded prognostic assessment. 


\section{EGFR Mutation Analyses}

Mutation analysis was performed in an institutional core facility regulated by the Clinical Laboratory Improvement Amendments as follows. EGFR gene mutations were analyzed in paraffin-embedded tissue sections from the primary tumor. Tumor tissue was scraped from the glass slides under direct visualization or under a dissecting microscope, and DNA was extracted with a QIAmp DNA Mini Kit (Qiagen, Valencia, CA). EGFR mutations were detected by DNA sequencing as follows. EGFR exons 18 to 21 were sequenced with a BigDye Terminator v3.1 Cycle Sequencing Kit (Applied Biosystems, Foster City, CA) after nested polymerase chain reaction as previously described. ${ }^{9}$

\section{Statistical Analysis}

This study was designed to detect an increase in the median survival time from 3.9 months in the historical control group ${ }^{7,8}$ to 6.0 months with this therapeutic approach. We used Fisher's exact test, the Wilcoxon rank sum test, and the Kruskal-Wallis test to compare patients with and without EGFR mutation with respect to clinical and demographic factors. We used the product-limit estimator of Kaplan and Meier to estimate overall survival, ${ }^{24}$ and we used the log-rank test to compare overall survival between groups defined by EGFR mutation status. We similarly analyzed CNS failure-free survival. Time to CNS failure was estimated considering death without CNS failure as a competing event by using the methods of Gooley et al. ${ }^{25}$ Differences between patients with known EGFR status (wild-type $v$ mutated) with respect to cumulative incidence of CNS failure were tested by the methods of Fine and Gray. ${ }^{26}$ Statistical tests were based on a two-sided significance level of 0.05 . All statistical analyses were performed by using SAS 9.3 for Windows (SAS Institute, Cary, NC).
Neurotoxicity was defined as a change in cognitive test performance that met or exceeded the reliable change index (RCI) value ${ }^{27}$ for each test. Test scores were assessed over time comparing patients' follow-up test scores with their baseline scores. A second set of analyses compared each subsequent test score with the patient's prior test score; constraints on sample size led to our analyzing changes from baseline to 1 year. Categories of RCI change (declined [ie, neurotoxicity], stable, or improved) were assigned at each follow-up time point. The incidence of neurotoxicity in this study was compared with that in the WBRT-alone group in a phase III study that used the same follow-up schedule and used several identical cognitive outcome variables. ${ }^{28}$ Differences in the proportion of patients who showed evidence of neurotoxicity at each follow-up time point were assessed by using Fisher's exact test to compare the $\mathrm{RCI}$ change status by group (erlotinib group $v$ historical control group).

\section{RESULTS}

\section{Patients}

Between January 2006 and October 2010, 40 patients were enrolled onto this study, all of whom had histologically proven NSCLC with radiographically confirmed brain metastases. Patient characteristics are provided in Table 1. The median age was 59 years (range, 29 to 77 years); 17 patients were male and 23 were female. Most patients $(\mathrm{n}=39)$ had a KPS of 70 to 90 and a median Diagnosis-Specific Graded Prognostic Assessment score ${ }^{29}$ of 1.5. Most patients $(n=29)$ were white, five were Latino, four were black, and two were Asian.

\begin{tabular}{|c|c|c|c|c|c|c|c|c|c|c|c|c|}
\hline \multirow[b]{3}{*}{ Adverse Event } & \multicolumn{12}{|c|}{ Grade } \\
\hline & \multicolumn{2}{|c|}{ Any } & \multicolumn{2}{|c|}{1} & \multicolumn{2}{|c|}{2} & \multicolumn{2}{|c|}{3} & \multicolumn{2}{|c|}{4} & \multicolumn{2}{|c|}{5} \\
\hline & No. & $\%$ & No. & $\%$ & No. & $\%$ & No. & $\%$ & No. & $\%$ & No. & $\%$ \\
\hline \multicolumn{13}{|l|}{ Constitutional symptoms } \\
\hline Fatigue & 24 & 60.0 & 5 & 12.5 & 14 & 35.0 & 5 & 12.5 & 0 & 0 & 0 & 0 \\
\hline Weight loss & 11 & 27.5 & 5 & 12.5 & 6 & 15.0 & 0 & 0 & 0 & 0 & 0 & 0 \\
\hline \multicolumn{13}{|l|}{ Dermatology } \\
\hline Alopecia & 16 & 40.0 & 10 & 25.0 & 6 & 15.0 & 0 & 0 & 0 & 0 & 0 & 0 \\
\hline Acneiform rash & 27 & 67.5 & 4 & 10.0 & 17 & 42.5 & 6 & 15.0 & 0 & 0 & 0 & 0 \\
\hline Radiation dermatitis & 4 & 10.0 & 1 & 2.5 & 3 & 7.5 & 0 & 0 & 0 & 0 & 0 & 0 \\
\hline Dry skin & 9 & 22.5 & 7 & 17.5 & 2 & 5.0 & 0 & 0 & 0 & 0 & 0 & 0 \\
\hline Pruritis & 4 & 10.0 & 3 & 7.5 & 1 & 2.5 & 0 & 0 & 0 & 0 & 0 & 0 \\
\hline Hand-foot syndrome & 2 & 5.0 & 0 & 0 & 2 & 5.0 & 0 & 0 & 0 & 0 & 0 & 0 \\
\hline \multicolumn{13}{|l|}{ Gastrointestinal } \\
\hline Anorexia & 7 & 17.5 & 4 & 10 & 3 & 7.5 & 0 & 0 & 0 & 0 & 0 & 0 \\
\hline Flatulence & 1 & 2.5 & 1 & 2.5 & 0 & 0 & 0 & 0 & 0 & 0 & 0 & 0 \\
\hline Diarrhea & 24 & 60.0 & 16 & 40.0 & 4 & 10.0 & 4 & 10.0 & 0 & 0 & 0 & 0 \\
\hline Nausea & 25 & 62.5 & 9 & 22.5 & 15 & 37.5 & 1 & 2.5 & 0 & 0 & 0 & 0 \\
\hline Vomiting & 14 & 35.0 & 5 & 12.5 & 7 & 17.5 & 2 & 5.0 & 0 & 0 & 0 & 0 \\
\hline Altered taste & 7 & 17.5 & 7 & 17.5 & 0 & 0 & 0 & 0 & 0 & 0 & 0 & 0 \\
\hline Dehydration & 10 & 25.0 & 1 & 2.5 & 5 & 12.5 & 4 & 10.0 & 0 & 0 & 0 & 0 \\
\hline \multicolumn{13}{|l|}{ Hepatobiliary } \\
\hline Increased AST/ALT & 2 & 5.0 & 1 & 2.5 & 0 & 0 & 1 & 2.5 & 0 & 0 & 0 & 0 \\
\hline Increased bilirubin & 4 & 10.0 & 0 & 0 & 3 & 7.5 & 1 & 2.5 & 0 & 0 & 0 & 0 \\
\hline \multicolumn{13}{|l|}{ Neurologic } \\
\hline Headache & 14 & 35.0 & 7 & 17.5 & 6 & 15.0 & 1 & 2.5 & 0 & 0 & 0 & 0 \\
\hline Dizziness & 2 & 5.0 & 1 & 2.5 & 1 & 2.5 & 0 & 0 & 0 & 0 & 0 & 0 \\
\hline \multicolumn{13}{|l|}{ Pulmonary } \\
\hline Cough & 6 & 15.0 & 5 & 12.5 & 1 & 2.5 & 0 & 0 & 0 & 0 & 0 & 0 \\
\hline Dyspnea & 2 & 5.0 & 1 & 2.5 & 1 & 2.5 & 0 & 0 & 0 & 0 & 0 & 0 \\
\hline Pleural effusion & 1 & 2.5 & 0 & 0 & 0 & 0 & 1 & 2.5 & 0 & 0 & 0 & 0 \\
\hline
\end{tabular}



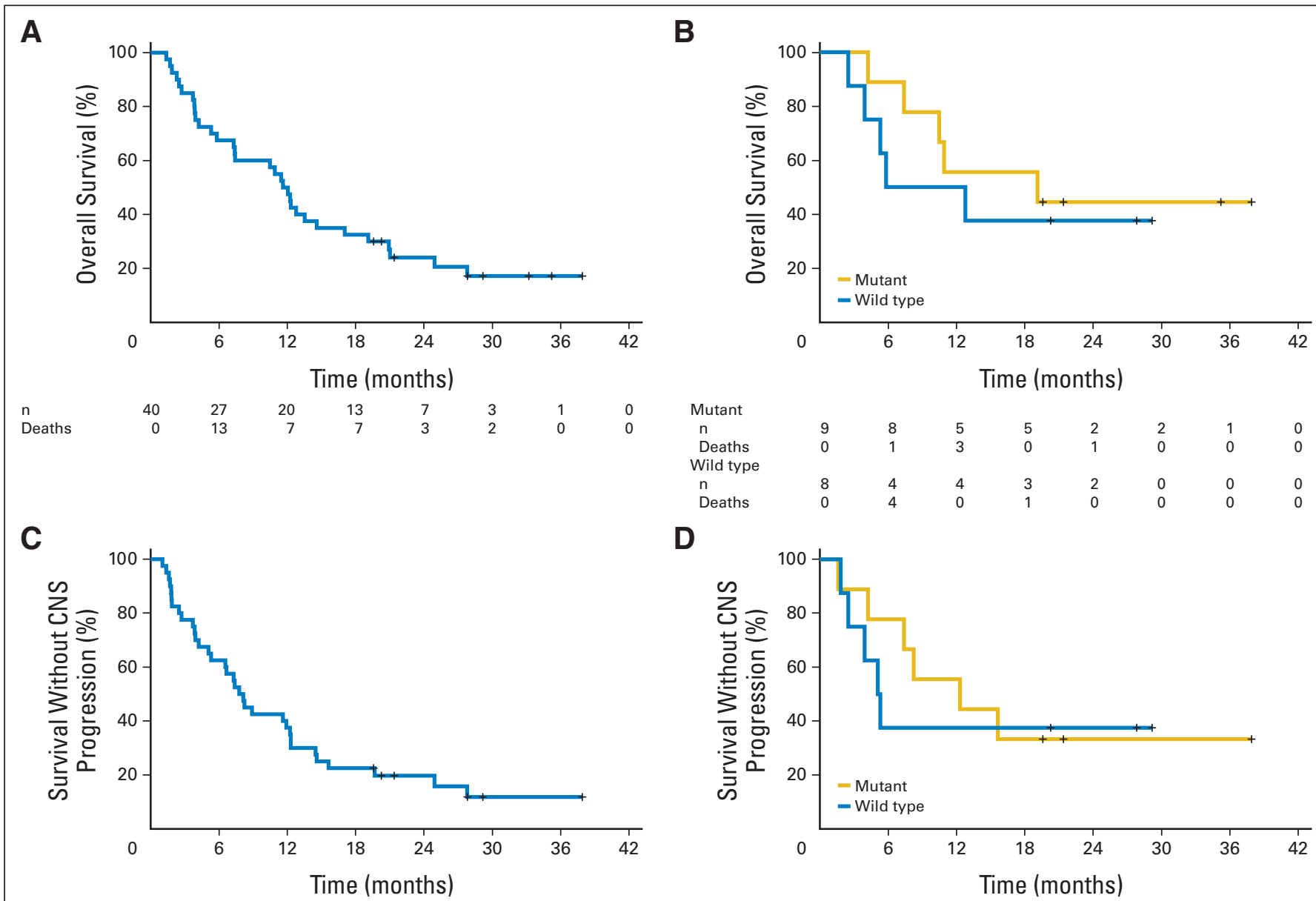

D
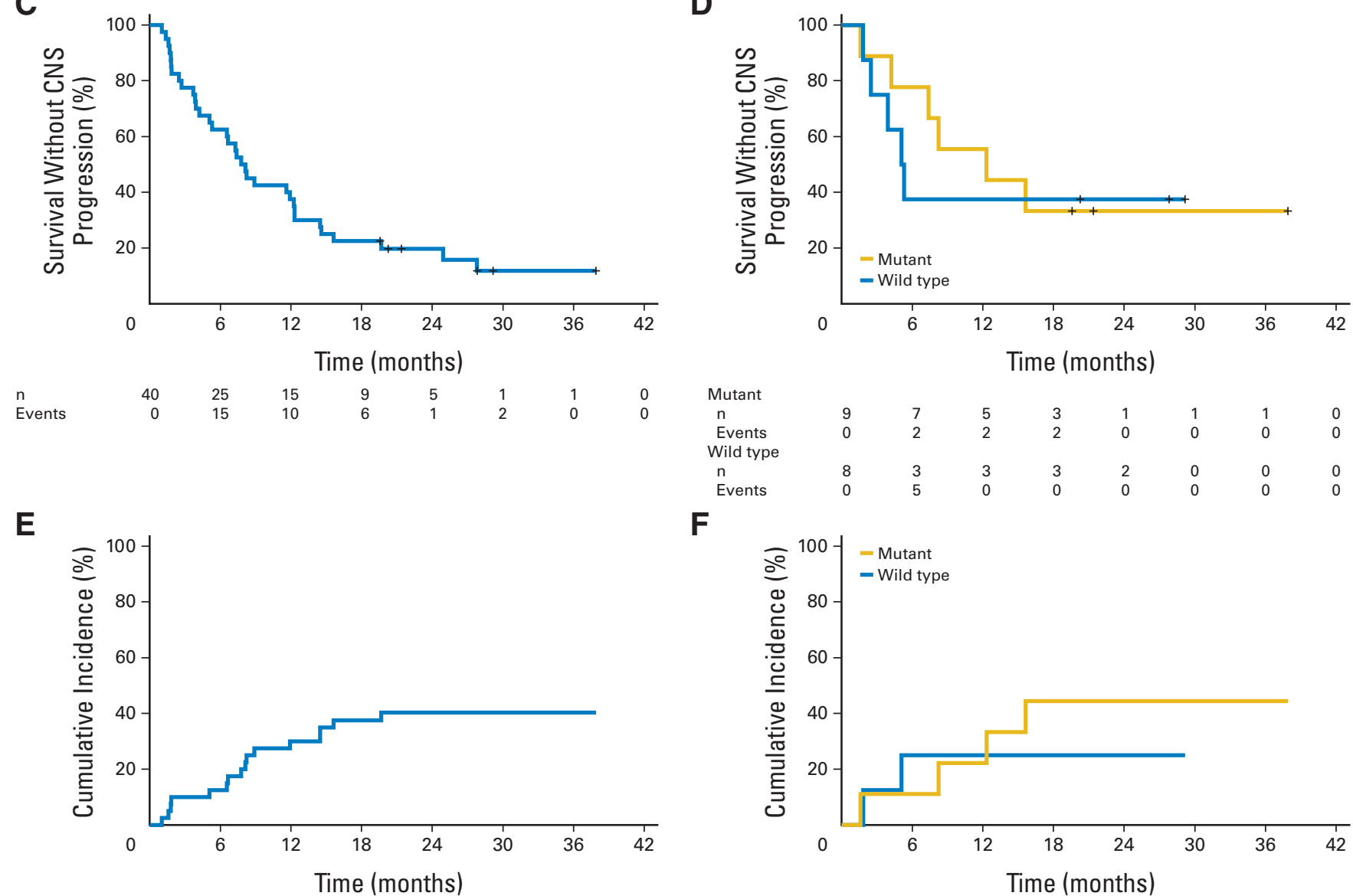

$\mathbf{F}$

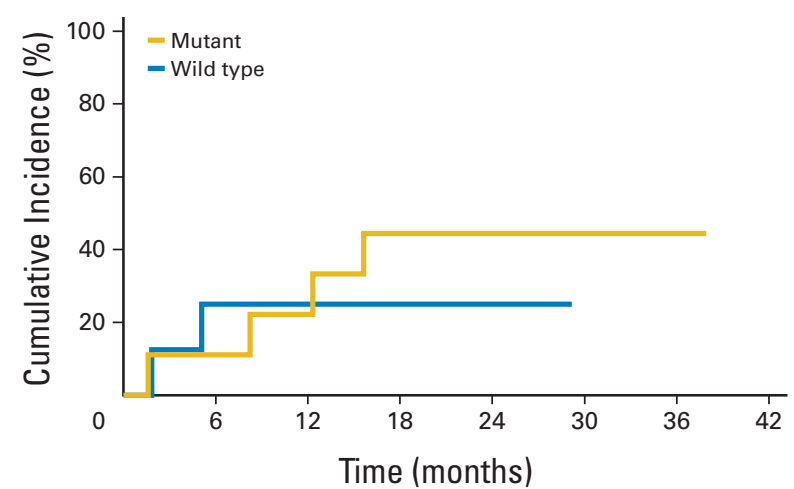

\begin{tabular}{|c|c|c|c|c|c|c|c|c|c|c|c|c|c|c|c|c|c|}
\hline $\mathrm{n}$ & 40 & 25 & 15 & 9 & 5 & 1 & 1 & 0 & Mutant & & & & & & & & \\
\hline \multirow{4}{*}{ Events } & 0 & 5 & 7 & 3 & 1 & 0 & 0 & 0 & $\mathrm{n}$ & 9 & 7 & 5 & 3 & 1 & 1 & 1 & 0 \\
\hline & & & & & & & & & $\begin{array}{l}\text { Events } \\
\text { Wild type }\end{array}$ & 0 & 1 & 1 & 2 & 0 & 0 & 0 & 0 \\
\hline & & & & & & & & & $\mathrm{n}$ & 8 & 3 & 3 & 3 & 2 & 0 & 0 & 0 \\
\hline & & & & & & & & & Events & 0 & 2 & 0 & 0 & 0 & 0 & 0 & 0 \\
\hline
\end{tabular}

Fig 1. Overall and CNS failure-free survival after treatment of brain metastases with whole-brain radiation therapy and erlotinib. Overall survival for (A) all patients

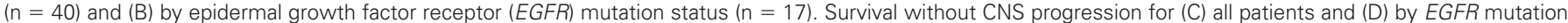
status. Cumulative incidence of CNS progression for (E) all patients and (F) by EGFR mutation status. 
Most patients had four or more brain metastases $(n=22 ; 55 \%)$, were prior smokers $(n=23 ; 57.5 \%)$, had adenocarcinomas $(n=30 ; 75 \%)$, and had documented extracranial disease on study entry $(n=28$; $70 \%$ ). Four patients had had stereotactic radiosurgery before study enrollment and five patients had stereotactic radiosurgery after completion of the study. The median number of lesions treated was three (range, one to six), and the median dose was $18 \mathrm{~Gy}$ (range, 15 to 22 Gy). Twenty-one patients had had chemotherapy before study enrollment, with the most common regimens being either cisplatin and docetaxel or carboplatin and paclitaxel. Two patients received pemetrexed.

\section{Toxicity}

The combination of erlotinib plus WBRT was well tolerated by all 40 patients. We saw no cases of radiation enhancing the erlotinibrelated rash in the portal treatment area. During the concurrent erlotinib plus WBRT phase, two patients required reduction of erlotinib dose because of an intense rash. Twenty-eight (70\%) of the 40 patients remained on erlotinib monotherapy for at least 1 month after completing WBRT (median time, 3 months; range, 1.3 to 28 months). The reason for stopping maintenance erlotinib varied, but most patients stopped early so they could start systemic chemotherapy. Use of erlotinib as first-line therapy was not standard during most of the period

\begin{tabular}{|c|c|c|c|c|c|c|c|c|}
\hline \multirow[b]{2}{*}{ Characteristic } & \multicolumn{2}{|c|}{$\begin{array}{c}\text { All Patients With } \\
\text { Known Mutation } \\
\text { Status }\end{array}$} & \multicolumn{2}{|c|}{$\begin{array}{l}\text { Patients With No } \\
\text { EGFR Mutations }\end{array}$} & \multicolumn{2}{|c|}{$\begin{array}{l}\text { Patients With } \\
\text { EGFR Mutations }\end{array}$} & \multirow[b]{2}{*}{$P$} & \multirow[b]{2}{*}{ Test } \\
\hline & No. & $\%$ & No. & $\%$ & No. & $\%$ & & \\
\hline Patients & 17 & & 8 & 47.1 & 9 & 52.9 & & \\
\hline \multicolumn{9}{|l|}{ Age, years } \\
\hline Median & \multicolumn{2}{|c|}{58} & \multicolumn{2}{|c|}{60.5} & \multicolumn{2}{|c|}{57} & .531 & Wilcoxon \\
\hline Range & \multicolumn{2}{|c|}{$29-71$} & \multicolumn{2}{|c|}{$29-71$} & \multicolumn{2}{|c|}{$42-68$} & & \\
\hline \multicolumn{9}{|l|}{ Sex } \\
\hline Female & 9 & 52.9 & 2 & 25.0 & 7 & 77.8 & .057 & Fisher's exact \\
\hline Male & 8 & 47.1 & 6 & 75.0 & 2 & 22.2 & & \\
\hline \multicolumn{9}{|c|}{ Karnofsky performance score } \\
\hline 90 & 6 & 35.3 & 4 & 50.0 & 2 & 22.2 & .213 & Kruskal-Wallis \\
\hline 80 & 8 & 47.1 & 4 & 50.0 & 4 & 44.4 & & \\
\hline 70 & 3 & 17.6 & 0 & 0.0 & 3 & 33.3 & & \\
\hline \multicolumn{9}{|l|}{ Race/ethnicity } \\
\hline White & 11 & 64.7 & 4 & 50.0 & 7 & 77.8 & .348 & Fisher's exact \\
\hline Hispanic or Latino & 3 & 17.6 & 1 & 12.5 & 2 & 22.2 & & \\
\hline Black & 2 & 11.8 & 2 & 25.0 & 0 & 0.0 & & \\
\hline Asian & 1 & 5.9 & 1 & 12.5 & 0 & 0.0 & & \\
\hline \multicolumn{9}{|c|}{ Number of brain metastases } \\
\hline $1-3$ & 5 & 29.4 & 2 & 25.0 & 3 & 33.3 & .574 & Kruskal-Wallis \\
\hline $4-10$ & 8 & 47.1 & 5 & 62.5 & 3 & 33.3 & & \\
\hline$>10$ & 4 & 23.5 & 1 & 12.5 & 3 & 33.3 & & \\
\hline \multicolumn{9}{|l|}{ Smoking status } \\
\hline Prior & 9 & 52.9 & 6 & 75.0 & 3 & 33.3 & .153 & Fisher's exact \\
\hline Never & 6 & 35.3 & 1 & 12.5 & 5 & 55.6 & & \\
\hline Current & 2 & 11.8 & 1 & 12.5 & 1 & 11.1 & & \\
\hline \multicolumn{9}{|l|}{ Tumor histology } \\
\hline Adenocarcinoma & 17 & 100.0 & 8 & 100.0 & 9 & 100.0 & & - \\
\hline \multicolumn{9}{|c|}{ Prior systemic chemotherapy } \\
\hline No & 9 & 52.9 & 4 & 50.0 & 5 & 55.6 & .999 & Fisher's exact \\
\hline Yes & 8 & 47.1 & 4 & 50.0 & 4 & 44.4 & & \\
\hline \multicolumn{9}{|c|}{ Steroids used during treatment } \\
\hline No & 5 & 29.4 & 1 & 12.5 & 4 & 44.4 & .294 & Fisher's exact \\
\hline Yes & 12 & 70.6 & 7 & 87.5 & 5 & 55.6 & & \\
\hline \multicolumn{9}{|l|}{ Extracranial disease } \\
\hline No & 5 & 29.4 & 2 & 25.0 & 3 & 33.3 & .999 & Fisher's exact \\
\hline Yes & 12 & 70.6 & 6 & 75.0 & 6 & 66.7 & & \\
\hline \multicolumn{9}{|l|}{ RECIST response } \\
\hline $\mathrm{CR}$ & 4 & 23.5 & 1 & 12.5 & 3 & 33.3 & 689 & Fisher's exact \\
\hline Mixed PR and CR & 1 & 5.9 & 1 & 12.5 & 0 & 0.0 & & \\
\hline$P R$ & 9 & 52.9 & 4 & 50.0 & 5 & 55.6 & & \\
\hline SD & 1 & 5.9 & 1 & 12.5 & 0 & 0.0 & & \\
\hline PD & 1 & 5.9 & 0 & 0.0 & 1 & 11.1 & & \\
\hline Unknown & 1 & 5.9 & 1 & 12.5 & 0 & 0.0 & & \\
\hline
\end{tabular}

Abbreviations: CR, complete response; EGFR, epidermal growth factor receptor; PD, progressive disease; PR, partial response; SD, stable disease. 
that this study was open. The toxicities experienced during the study are listed in Table 2. No grade 4 or grade 5 treatment-related toxicity was seen. The most common type of toxicity was acneiform rash ( $\mathrm{n}=27 ; 67.5 \%$; six patients [15\%] had a grade 3 rash). During long-term follow-up, two patients developed questionable neurotoxicity that was deemed possibly related to treatment. The first of these patients was a 74-year-old man who developed symptoms of dementia at 2 years after study completion; after this incident, the maximum age limit was reduced to 70 years. The second patient was a 65 -year-old woman who developed progressive CNS disease 5 months after completion of WBRT. She went on to receive a stereotactic radiosurgery boost and later developed radiation necrosis. A craniotomy intended to treat this necrosis led to resection of Broca's area, rendering the patient aphasic and making neurotoxicity difficult to ascertain. No statistically significant differences were found between the erlotinib group and the historical control group in the proportion of patients with evidence of neurotoxicity at any of the time points examined, regardless of whether the comparison was change from baseline or change from the previous last test score.

\section{Outcomes}

Eight patients were alive at the time of this analysis, and the median follow-up time was 28.5 months (range, 19.6 to 37.9 months). The 6-month, 1-year, and 2-year overall survival rates were $68 \%, 50 \%$, and $24 \%$. The median overall survival time was 11.8 months (95\% CI, 7.4 to 19.1 months), which is almost double the 6 months the study was designed to detect. The 6-month, 1-year, and 2-year cumulative rates of CNS progression were $13 \%, 30 \%$, and $40 \%$. The 6-month, 1 -year, and 2-year CNS progression-free survival rates were $63 \%$, $38 \%$, and $20 \%$, and the median CNS progression-free survival time was 8.0 months (Fig 1).

The CNS response rates between 3 and 6 months (according to RECIST) were $31 \%$ complete response $(n=11), 56 \%$ partial response $(\mathrm{n}=20), 6 \%$ mixed (complete and partial) response $(\mathrm{n}=2), 6 \%$ progressive disease $(n=2)$, and $3 \%$ stable disease $(n=1)$, for an overall response rate of $86 \%$ among those assessed for response. The most prevalent site of first failure was extra-axial or systemic in 21 patients $(52.5 \%)$, CNS in nine patients $(22.5 \%)$, both the brain and systemically in two patients (5\%), and in unknown sites in two patients (5\%); six patients (15\%) had not experienced failure, either systemically or in the brain. Overall, 16 patients (40\%) experienced CNS failure at some point after treatment. The median survival times were similar for patients with three or more lesions (12.2 months) and for those with four or more lesions (11.5 months; $P=.638)$, and the overall median survival time was 11.8 months.

\section{EGFR Mutation Status}

To our surprise, EGFR mutations were present in nine of the 17 patients for whom the EGFR status of the primary lung tumor was known (Table 3). The most common mutation was a deletion in exon 19 (five patients), followed by deletion in exon 21 (two patients). More of the patients with mutated EGFR were female (78\%). Grade 2 or greater rash seemed more common among patients with EGFR mutations (seven patients with mutations $v$ five with wild type); all three of the patients who developed grade 3 rash had EGFR mutations. Five of the nine patients with mutations had never smoked. The duration of maintenance erlotinib was associated with EGFR mutation status: the median duration was 111 days (range, 80 to 288 days) for the nine patients with mutations versus 45 days (range, 26 to 159 days) for the eight patients without mutations $(P=.034)$. The 3 -month CNS response rate (complete plus partial responses) was $89 \%$ for patients with EGFR mutations versus $63 \%$ for patients with wild-type EGFR. The RECIST rates of complete response, partial response, mixed response, stable disease, and progressive disease were 33\%, 56\%, $0 \%$, $0 \%$, and $11 \%$ for patients with EGFR mutations and $12.5 \%, 50 \%$, $12.5 \%, 12.5 \%$, and $0 \%$ for patients with wild-type EGFR. One patient with wild-type EGFR had an unknown response. The median overall survival times were also different according to EGFR mutation status: 9.3 months for the EGFR wild-type group and 19.1 months for the EGFR mutation group (lower 95\% confidence bound, 10.5 months). At the time of analysis, four of the nine patients with EGFR mutations were alive, all of whom had exon 19 deletions; however, this apparent difference was not statistically significant $(P=.534)$. Survival times and rates according to EGFR mutation status are shown in Figure 1 and Table 4. Times to CNS progression and CNS progression-free survival for these 17 patients are also summarized in Table 4.

\section{DISCUSSION}

These mature results from a multi-institutional phase II study showed that WBRT with concurrent erlotinib for NSCLC produced longer overall survival compared with that of historical controls, with particular benefit evident for patients with EGFR mutations. ${ }^{7,8}$ We further found that the rate of EGFR-mutated primary tumors in this group was much higher than expected. Numerous publications have indicated an EGFR mutation rate of approximately $10 \%$ to $15 \%$ in $\mathrm{NSCLC}^{11}$; the rate in our study of unselected patients with brain metastasis was $50 \%$. Moreover, to the best of our knowledge, this is the first report of EGFR mutations in primary NSCLC tumors in patients with brain metastases.

\begin{tabular}{|c|c|c|c|c|}
\hline \multirow[b]{2}{*}{ Outcome } & $\begin{array}{c}\text { All } \\
\text { Patients } \\
(\mathrm{N}=17)\end{array}$ & $\begin{array}{c}\text { Patients } \\
\text { With No } \\
\text { EGFR } \\
\text { Mutations } \\
(\mathrm{n}=8)\end{array}$ & $\begin{array}{l}\text { Patients } \\
\text { With } \\
\text { EGFR } \\
\text { Mutations } \\
(\mathrm{n}=9)\end{array}$ & \multirow[b]{2}{*}{$P$} \\
\hline & No. $\%$ & No. & No. & \\
\hline \multicolumn{5}{|l|}{ Overall survival } \\
\hline Median time, months & 12.8 & 9.3 & 19.1 & .534 \\
\hline 6-month rate & 70.6 & 50.0 & 88.9 & \\
\hline 1-year rate & 52.9 & 50.0 & 55.6 & \\
\hline 2-year rate & 41.2 & 37.5 & 44.4 & \\
\hline \multicolumn{5}{|c|}{$\begin{array}{l}\text { Cumulative incidence of CNS } \\
\text { progression }\end{array}$} \\
\hline Median time, months & $\mathrm{N} / \mathrm{R}$ & $\mathrm{N} / \mathrm{R}$ & $\mathrm{N} / \mathrm{R}$ & .507 \\
\hline 6-month rate & 17.6 & 25.0 & 11.1 & \\
\hline 1-year rate & 23.5 & 25.0 & 22.2 & \\
\hline 2-year rate & 35.3 & 25.0 & 44.4 & \\
\hline \multicolumn{5}{|c|}{ CNS progression-free survival } \\
\hline Median time, months & 8.2 & 5.2 & 12.3 & .742 \\
\hline 6-month rate & 58.8 & 37.5 & 77.8 & \\
\hline 1-year rate & 47.1 & 37.5 & 55.6 & \\
\hline 2-year rate & 35.3 & 37.5 & 33.3 & \\
\hline
\end{tabular}


EGFR mutation testing is now commonplace in the diagnosis and treatment of NSCLC. When several randomized trials demonstrated a survival advantage for patients with metastatic NSCLC who were given erlotinib, this drug was soon approved for refractory NSCLC, after which several studies were undertaken to stratify patients further according to EGFR mutation status. Mutation status seems to be the strongest correlate of response to anti-EGFR targeting agents, ${ }^{9}$ a finding that is also supported by our results. In this study of patients with biopsy-proven NSCLC and radiographic evidence of brain metastases, EGFR mutations were found in approximately $50 \%$ of the 17 patients in whom EGFR mutation status had been tested. Given the differences in biologic properties and molecular signaling pathways associated with EGFR mutations, one might surmise that tumors with EGFR mutations have a different biologic profile or path of spread than do wild-type EGFR tumors. Response to EGFRtargeting agents has also been associated with the epithelial-tomesenchymal transition in that tumors with a stronger epithelial phenotype tend to respond much better to EGFR-targeting agents than do tumors with a predominantly mesenchymal phenotype. This might explain, in part, why patients with EGFR mutations may be more prone to brain metastases than patients with nonmutated tumors. This supposition is supported by a report from Matsumoto et $\mathrm{al}^{30}$ that 12 of 19 metastatic brain lesions from lung cancer had EGFR mutations.

Although these findings are thought provoking, they must be interpreted cautiously because of the small numbers of patients and lack of randomization. Moreover, this study was probably subject to a negative selection bias, because MD Anderson commonly treats patients with four or fewer CNS lesions with a stereotactic approach. Moreover, the use of erlotinib has changed significantly since this trial was begun; currently erlotinib is approved for use as initial treatment (first-line therapy) for patients with a new diagnosis of EGFR-mutated lung cancer. This usage would presumably lead to outcomes that are different from those for the patients in this trial.

In conclusion, this trial of concurrent erlotinib and radiation therapy for the initial treatment of brain metastases from NSCLC showed that this combination was safe and well tolerated. The percentage of patients with mutated EGFR was much higher than is typical of unselected patients with NSCLC. Survival times for all patients in this trial exceeded those expected from historical controls, and the benefits seemed exceptionally high for patients with EGFR mutation rates. Larger prospective randomized clinical trials are needed to validate our findings and confirm these suppositions.

\section{AUTHORS' DISCLOSURES OF POTENTIAL CONFLICTS OF INTEREST}

Although all authors completed the disclosure declaration, the following author(s) and/or an author's immediate family member(s) indicated a financial or other interest that is relevant to the subject matter under consideration in this article. Certain relationships marked with a " $U$ " are those for which no compensation was received; those relationships marked with a " $C$ " were compensated. For a detailed description of the disclosure categories, or for more information about ASCO's conflict of interest policy, please refer to the Author Disclosure Declaration and the Disclosures of Potential Conflicts of Interest section in Information for Contributors. Employment or Leadership Position: None Consultant or Advisory Role: Edward S. Kim, Genentech (C), OSI Pharmaceuticals (C) Stock Ownership: None Honoraria: John V. Heymach, Genentech; Edward S. Kim, Genentech, OSI Pharmaceuticals Research Funding: None Expert Testimony: None Other Remuneration: None

\section{AUTHOR CONTRIBUTIONS}

Conception and design: James W. Welsh, Ritsuko Komaki, Linda L.

Garland, Su S. Chen, Baldassarre Stea

Collection and assembly of data: Arya Amini, Wyatt Unger, Pamela K. Allen, Joe Y. Chang, Jeffrey S. Wefel, Jamie Holt, Baldassarre Stea Data analysis and interpretation: Mark F. Munsell, Jeffrey S. Wefel, Susan L. McGovern, Zhongxing Liao, Paul Brown, Erik Sulman, John V. Heymach, Edward S. Kim

Manuscript writing: All authors

Final approval of manuscript: All authors

\section{REFERENCES}

1. Jemal $A$, Siegel $R, X u J$, et al: Cancer statistics, 2010. CA Cancer J Clin 60:277-300, 2010

2. Mujoomdar A, Austin JH, Malhotra R, et al: Clinical predictors of metastatic disease to the brain from non-small cell lung carcinoma: Primary tumor size, cell type, and lymph node metastases. Radiology 242:882-888, 2007

3. Barnholtz-Sloan JS, Sloan AE, Davis FG, et al: Incidence proportions of brain metastases in patients diagnosed (1973 to 2001) in the Metropolitan Detroit Cancer Surveillance System. J Clin Oncol 22:2865-2872, 2004

4. Verger E, Gil M, Yaya R, et al: Temozolomide and concomitant whole brain radiotherapy in patients with brain metastases: A phase II randomized trial. Int J Radiat Oncol Biol Phys 61:185191, 2005

5. Sperduto PW, Berkey B, Gaspar LE, et al: A new prognostic index and comparison to three other indices for patients with brain metastases: An analysis of 1,960 patients in the RTOG Database. Int J Radiat Oncol Biol Phys 70:510-514, 2008
6. Gaspar L, Scott C, Rotman M, et al: Recursive partitioning analysis (RPA) of prognostic factors in three Radiation Therapy Oncology Group (RTOG) brain metastases trials. Int J Radiat Oncol Biol Phys 37:745-751, 1997

7. Knisely JP, Berkey B, Chakravarti A, et al: A phase III study of conventional radiation therapy plus thalidomide versus conventional radiation therapy for multiple brain metastases (RTOG 0118). Int J Radiat Oncol Biol Phys 71:79-86, 2008

8. McHaffie DR, Chabot $P$, Dagnault $A$, et al: Safety and feasibility of motexafin gadolinium administration with whole brain radiation therapy and stereotactic radiosurgery boost in the treatment of $\leq 6$ brain metastases: A multi-institutional phase II trial. J Neurooncol 105:301-308, 2011

9. Lynch TJ, Bell DW, Sordella R, et al: Activating mutations in the epidermal growth factor receptor underlying responsiveness of non-small-cell lung cancer to gefitinib. N Engl J Med 350:2129-2139, 2004

10. Neal JW: The SATURN trial: The value of maintenance erlotinib in patients with non-small-cell lung cancer. Future Oncol 6:1827-1832, 2010

11. Roberts PJ, Stinchcombe TE, Der CJ, et al: Personalized medicine in non-small-cell lung cancer: Is KRAS a useful marker in selecting patients for epidermal growth factor receptor-targeted therapy? J Clin Oncol 28:4769-4777, 2010

12. Chinnaiyan $P$, Huang $S$, Vallabhaneni $G$, et al: Mechanisms of enhanced radiation response following epidermal growth factor receptor signaling inhibition by erlotinib (Tarceva). Cancer Res 65:3328-3335, 2005

13. Chen DJ, Nirodi CS: The epidermal growth factor receptor: A role in repair of radiationinduced DNA damage. Clin Cancer Res 13:65556560, 2007

14. Akimoto $T$, Hunter NR, Buchmiller $L$, et al: Inverse relationship between epidermal growth factor receptor expression and radiocurability of murine carcinomas. Clin Cancer Res 5:2884-2890, 1999

15. Togashi $Y$, Masago K, Fukudo M, et al: Cerebrospinal fluid concentration of erlotinib and its active metabolite OSI-420 in patients with central nervous system metastases of non-small cell lung cancer. J Thorac Oncol 5:950-955, 2010

16. Weber B, Winterdahl M, Memon A, et al: Erlotinib accumulation in brain metastases from non-small cell lung cancer: Visualization by positron emission tomography in a patient harboring a mutation in the epidermal growth factor receptor. J Thorac Oncol 6:1287-1289, 2011 
17. Fowler JF: The radiobiology of prostate cancer including new aspects of fractionated radiotherapy. Acta Oncol 44:265-276, 2005

18. Correa DD, DeAngelis LM, Shi W, et al: Cognitive functions in survivors of primary central nervous system lymphoma. Neurology 62:548-555, 2004

19. Correa DD, Rocco-Donovan M, DeAngelis $L M$, et al: Prospective cognitive follow-up in primary CNS lymphoma patients treated with chemotherapy and reduced-dose radiotherapy. J Neurooncol 91: 315-321, 2009

20. Hottinger AF, DeAngelis LM, Yahalom J, et al: Salvage whole brain radiotherapy for recurrent or refractory primary CNS lymphoma. Neurology 69: 1178-1182, 2007

21. Chao JH, Phillips $R$, Nickson JJ: Roentgen-ray therapy of cerebral metastases. Cancer 7:682-689, 1954
22. Folstein MF, Folstein SE, McHugh PR: "Minimental state": A practical method for grading the cognitive state of patients for the clinician. J Psychiatr Res 12:189-198, 1975

23. European Organisation for Research and Treatment of Cancer: Common Toxicity Criteria (CTC). http:// www.eortc.be/services/doc/ctc/default.htm

24. Kaplan EL, Meier P: Nonparametric estimation from incomplete observations. J Am Stat Assoc 53:457-481, 1958

25. Gooley TA, Leisenring W, Crowley J, et al: Estimation of failure probabilities in the presence of competing risks: New representations of old estimators. Stat Med 18:695-706, 1999

26. Jason PF, Gray RJ: A proportional hazards model for the subdistribution of a competing risk. J Am Stat Assoc 94:496-509, 1999
27. Wefel JS, Cloughesy $T$, Zazzali JL, et al: Neurocognitive function in patients with recurrent glioblastoma treated with bevacizumab. Neuro Oncol 13:660-668, 2011

28. Mehta MP, Rodrigus $P$, Terhaard $C H$, et al: Survival and neurologic outcomes in a randomized trial of motexafin gadolinium and whole-brain radiation therapy in brain metastases. J Clin Oncol 21:2529-2536, 2003

29. Sperduto PW, Chao ST, Sneed PK, et al: Diagnosis-specific prognostic factors, indexes, and treatment outcomes for patients with newly diagnosed brain metastases: A multi-institutional analysis of 4,259 patients. Int J Radiat Oncol Biol Phys 77:655-661, 2010

30. Matsumoto S, Takahashi K, Iwakawa R, et al: Frequent EGFR mutations in brain metastases of lung adenocarcinoma. Int J Cancer 119:1491-1494, 2006

\section{QOPI: Assess and Improve Care in Your Medical Oncology Practice}

Obtaining reliable data about the care you provide can be a challenge. That's why ASCO created the Quality Oncology Practice Initiative $\left(\mathrm{QOPI}{ }^{\circledR}\right)$, designed to promote excellence in cancer care by helping oncologists create a culture of selfexamination and improvement. In addition, ASCO offers the QOPI Certification Program to recognize QOPI participants who achieve rigorous standards for cancer care.

Benefits of participation in ASCO's quality assessment and improvement program for outpatient hematology-oncology practices include:

- Practice-specific and comparative data

- QOPI Health Plan Program

- ABIM maintenance of certification practice improvement

- CME credit

- Fellowship program quality improvement experience

The QOPI Certification designation can be used by certified practices to demonstrate an advanced commitment to quality. Visit qopi.asco.org to learn more. 